\title{
La tasca arqueològica de Ferran de Sagarra i de Siscar ${ }^{1}$
}

\section{Ferran de Sagarra $i$ de Siscar and archaeology}

L'objectiu d'aquest article és analitzar la tasca arqueològica de Ferran de Sagarra i de Siscar. Per això ens centrarem en tres aspectes concrets: la seva col-laboració amb les institucions catalanes relacionades amb l'arqueologia, la seva col-lecció d'antiguitats i, sobretot, les seves excavacions al Puig Castellar.

Paraules clau: Puig Castellar, Juan Rubio de la Serna, Asociación Artístico-Arqueológica de Barcelona, Associació Catalanista d'Excursions Científiques.
This paper analyses the archaeological work of Ferran de Sagarra i de Siscar by focusing on three main aspects: his collaboration with archaeological institutions in Catalonia, his private collection of artefacts, and, in particular, his excavations at the site of Puig Castellar.

Keywords: Puig Castellar, Juan Rubio de la Serna, Asociación Artístico-Arqueológica de Barcelona, Associació Catalanista d'Excursions Científiques.
1. Agraeixo a Míriam Vaca (Reial Acadèmia de Bones Lletres de Barcelona), Anna Font (Institut d'Estudis Catalans) i Anna Gudayol (Biblioteca de Catalunya) les facilitats que em donaren per la consulta de la documentació de Ferran de Sagarra dipositada a les esmentades institucions. Agraeixo també a Jordi Cortadella i Lluís Feliu la lectura i remarques que feren del manuscrit. Per descomptat, els errors són responsabilitat meva. 


\section{Introducció}

Ferran de Sagarra i de Siscar (Barcelona, 1853 Saint-Sulpice-La-Pointe, Llenguadoc, 1939), llicenciat en dret civil i canònic per la Universitat de Barcelona (1875), va ser un reconegut sigil-lògraf i historiador que, a més, va portar a terme una meritòria tasca arqueològica. Al càrrec d'un ric patrimoni familiar en decadència, Sagarra disposà de les rendes suficients per dedicar la seva vida a desenvolupar una ingent tasca historiogràfica pel seu compte, al marge de qualsevol obligació acadèmica o universitària. ${ }^{2}$ És ben cert que en el marc de la seva trajectòria intel-lectual, l'arqueologia de camp ocupa un paper secundari, sobretot si ho comparem amb la qualitat i quantitat de les seves aportacions en el camp de la sigil-lografia i la història de la Catalunya moderna. No obstant això, la seva tasca arqueològica resultà prou significativa, amb alguns trets que mereixen ser destacats dins del context històric de l'arqueologia catalana de la fi del segle XIX i principi del xx. La seva gran aportació en aquest àmbit, com veurem, van ser les excavacions pioneres al poblat ibèric de Puig Castellar. Amb tot, el seu interès en la disciplina arqueològica no es limità a dites excavacions, sinó que fou una veritable constant al llarg de la seva vida, com ho demostra el fet que fos corresponent de la Societat Arqueològica Tarraconense i membre de la Societat Artístico-Arqueològica de Barcelona, entre d'altres.

Amb tot, la vessant arqueològica de Sagarra sovint ha estat menystinguda i/o oblidada. En aquest sentit resulta molt significativa la seva absència a la síntesi de Xavier Barral sobre la història de l'arqueologia a Catalunya (Barral 1989), o la no inclusió d'una entrada dedicada a la seva figura dins del diccionari d'història de l'arqueologia a Espanya, editat recentment per Margarita Díaz-Andreu, Gloria Mora i Jordi Cortadella (Díaz-Andreu / Mora / Cortadella 2009). A l'estudi de Francisco Gracia i Jordi Cortadella sobre la institucionalització de l'arqueologia a Catalunya hi trobem dos apartats introductoris on tampoc no s'esmenta la figura de Sagarra al costat d'altres pioners com Lluís Marià Vidal o Juan Rubio de la Serna, que sí que tenen el seu espai (Gracia / Cortadella 2007). Igualment destacable és el fet que a l'entrada que es dedica a Sagarra al Diccionari d'Historiografia Catalana en cap moment s'esmentin les seves aportacions arqueològiques (Espino 2003). ${ }^{3}$ L'objectiu d'aquest treball és el de reconstruir i analitzar la trajectòria arqueològica de Ferran de Sagarra per, d'aquesta manera, destacar en la justa mesura el seu paper com un dels pioners de l'arqueologia al nostre país.

\section{El col-leccionisme d'antiguitats}

Sagarra, certament, va ser un gran col-leccionista, sobretot de segells, però també de peces arqueològi-

2. Per a una aproximació biogràfica a la figura de Ferran de Sagarra vegeu Serra 2005.

3. Altres treballs, en canvi, sí que fan referència al paper de Sagarra com a pioner de l'arqueologia a Catalunya (vegeu, per exemple, Marc-7 1986: 56). ques, fet que ens ajuda a dimensionar correctament la seva figura en relació amb l'arqueologia.

La seva col-lecció de segells va rebre en el seu moment tota mena d'elogis, obtenint un reconeixement social i acadèmic destacable. Un bon testimoni de la seva rellevància ens l'ofereix la crònica d'una visita a l'esmentada col-lecció per part d'alguns socis del Centre Excursionista de Catalunya el juny de 1893. Segons es recull a dita crònica, la col-lecció de Sagarra constava de més de 15.000 segells, tant originals com reproduccions, i estava perfectament ordenada en sèries o seccions (comtes de Barcelona, reis d'Aragó, reis de Castella, etc.), cadascuna de les quals tenia el seu corresponent catàleg (Anònim 1893).

Pel que fa a la seva col-lecció de peces arqueològiques, el seu fill, Josep Maria de Sagarra, recordava a les seves memòries com el pare habilità com a petit museu arqueològic una de les habitacions de la casa familiar del carrer dels Mercaders número 33 de Barcelona. Segons explica l'escriptor, la cambra museu del pare adquirí cert renom a principi de segle entre l'alta societat barcelonina, i va rebre visites de personalitats com Fidel Fita, Norbert Font i Sagué i Josep Pijoan, entre d'altres (Sagarra 1954: 321 s.).

Ara bé, quines peces exposava Sagarra a la seva cambra museu i com ho feia? Malauradament, les fonts en aquest sentit són gasives. No he trobat entre la documentació de Sagarra cap mena d'inventari de peces, ni tampoc cap representació gràfica de la sala que ens permeti reconstruir el seu aspecte i la disposició dels objectes. Per sort, alguns dels visitants de la cambra museu, als quals Sagarra feia signar en el seu llibre de registre, ens han llegat algunes breus descripcions del lloc. En aquest sentit potser cal destacar el testimoni de Lluís Nicolau d'Olwer, qui explica que Francesc Carreras i Candi tenia per costum portar els seus estudiants d'història de Catalunya dels Estudis Universitaris Catalans a visitar el petit museu de Sagarra, com una activitat més dins del seu procés de formació en la matèria. Nicolau d'Olwer va ser un d'aquells estudiants, i va deixar testimoni escrit de la seva experiència a la casa dels Sagarra:

Una bella tarda, a la seva casa pairal del carrer de Mercaders - aterrada després per la Reforma- el senyor Sagarra ens va rebre i, amb llenguatge planer de l'home que domina la matèria, va anar-nos explicant els punts cabdals de la sigil-lografia i mostrant-nos els exemplars més interessants de la seva col-lecció. Va dur-nos després a una altra cambra, on tenia el material extret de les seves excavacions del Puig Castellar, a Santa Coloma de Gramanet (encara en veig uns cranis travessats de claus), i va acomiadar-nos, senzill i afable, repartint-nos, record d'aquella visita, la seva memòria Importància de la sigil.lografia com a ciència auxiliar de la història (Nicolau d'Olwer 1958: 145 s.).

Segons es desprèn del testimoni de Nicolau d'Olwer la cambra museu de Sagarra era en realitat una mena de magatzem dels materials trobats a les excavacions del Puig Castellar, destacant especialment els cranis enclavats als quals ens referirem més endavant. Cal suposar, per tant, que Sagarra exposava a casa seva les principals peces trobades al jaciment: abundant material ceràmic (tant grec com, sobretot, ibèric), toves de fang, pedres de molí, gresols de fundició, 
eines d'os, objectes de bronze (tanques de cinturó, fíbules...) i ferro (espases, aixades, falçs, claus...), peces de teler, així com abundants restes òssies humanes, entre les quals destacaven, és clar, els cranis enclavats (Bosch Gimpera 1923: 594 s.).

Amb tot, altres testimonis deixen entreveure que Sagarra conservava també altres materials arqueològics, a banda dels extrets del Puig Castellar. En les seves memòries, tot i que sense entrar en gaires detalls al respecte, Josep Maria de Sagarra afirmava que el seu pare col-leccionava també fragments de ceràmica romana procedents d'una finca familiar de Valls, ${ }^{4}$ així com una col-lecció de monedes romanes que, segons sembla, eren fàcils d'aconseguir en aquells temps:

D'aquelles monedes romanes, en circularen en gran quantitat fins després de la Revolució de Setembre $i$ es donava a cada una el valor d'un xavo (Sagarra 1954: 264).

En qualsevol cas, i segons es desprèn del testimoni de Josep Maria de Sagarra, no sembla que aquells materials formessin part de la cambra museu de la casa familiar. De fet, afirma l'escriptor que ceràmica i monedes es conservaven entre els "malendreços" del seu pare, sense un control gaire estricte:

De la terrissa i dels xavos, el meu pare me'n deixà fer una tria, amb la qual vaig guarnir el meu primer escriptori, clavant amb xinxetes a la paret alguns gravats antics procedents d'una incompleta enciclopèdia històrica, que representaven figures egrègies de la cultura o del poder dels romans (Sagarra 1954: 264).

En qualsevol cas, i reconeixent la nostra incapacitat per aconseguir dades més precises sobre la composició exacta de la col-lecció, podem concloure amb raonable certesa que Sagarra reuní peces arqueològiques sense una pretensió científica clara. Més aviat, pel que sabem, la seva era una col-lecció de materials "familiars", és a dir, de peces arqueològiques exhumades del terra de les seves propietats (sobretot del Puig Castellar) i agrupades en un espai concret de la casa, que Sagarra ensenyava amb delit al més florit de l'erudició catalana de principi del segle xx.

En aquest sentit, la figura de Sagarra encaixa perfectament a l'ambient de l'època, on eren relativament freqüents aquesta mena de petits museus arqueològics familiars. Sens dubte el cas més significatiu, també per la seva relació amb Sagarra, va ser la col-lecció arqueològica reunida per Juan Rubio de la Serna a la seva casa de Sant Andreu de Llavaneres. La col-lecció estava formada per més de 150 objectes procedents de la necròpolis ibèrica de Casa Rodón de l'Horta (Cabrera de Mar). La finca on es trobava el jaciment era propietat de la família Rubio, i fou el mateix Juan Rubio l'encarregat de l'excavació des de 1881. En aquest cas coneixem bé el contingut de la col-lecció gràcies a la descripció que el 1926 en va fer Josep de Calassanç Serra Ràfols (Serra Ràfols 1926). Així, els materials reunits per Rubio a casa seva eren essencialment urnes cineràries, petits recipients ceràmics que contenien les ofrenes als difunts,

4. Vegeu Serra 2005: 8 sobre la incorporació de la finca de Valls al patrimoni de la família Sagarra a la darreria del segle XvII. vasos d'importació grecs, armes, fíbules, tanques de cinturó, etc.

De fet, gràcies a l'esborrany d'una carta de Sagarra a Rubio, conservat a la Biblioteca de Catalunya, ${ }^{5}$ i que probablement hem de datar al 1904, sabem que el primer planejava visitar la col-lecció de Rubio a Sant Andreu de Llavaneres. Segons explica Sagarra al text, l'objectiu de la seva visita a Rubio era doble. D'una banda, conèixer la col-lecció dels materials de Cabrera (segurament per trobar un model a partir del qual organitzar la seva pròpia col-lecció):

Muy Sr. mío y de mi mayor consideracion. No se si recordará $\mathrm{V}$. que el dia de su recepción en nuestra Acad $^{\mathrm{a}}$ de Buenas Letras tuve el honor de ser presentado a V. por el amigo Carreras Candi y hablamos del notabilísimo museo por V. reunido como parte de las excavaciones practicadas en su finca de Cabrera.

De l'altra, per comentar amb Rubio les seves pròpies excavacions al Puig Castellar i analitzar entre tots dos quines eren les millors estratègies d'excavació:

Si no temiese abusar de su amabilidad le pediría permiso para visitarlo, y ver el lugar donde se encontró ese riquísimo tesoro arqueologico y a la vez recibiria de V. con agrado algunas indicaciones y reglas para realizar con exito semejantes excavaciones, pues me encuentro siguiendo una pista que tal vez de por resultado el hallazgo de otro tesoro arqueologico en una finca de mi propiedad.

Como en estos trabajos para no andar á tientas y hacerlos fructiferos es conveniente seguir los consejos y comentarios de la experiencia, tendría mucho gusto en oír los de V. que indudablemente me serían muy provechosos.

Com ja ha assenyalat Jordi Cortadella, les figures de Ferran de Sagarra i Juan Rubio de la Serna són perfectament paral-leles (Cortadella 2004: 172). Tots dos són clars exemples d'allò que podríem definir com arqueòlegs diletants i col-leccionistes que, al marge del món acadèmic, dedicaren una part important del seu temps a l'estudi de qüestions relacionades amb l'arqueologia i, en aquests dos casos concrets, a l'excavació de jaciments arqueològics "familiars". Són figures típiques de la darreria del segle XIX i principi del $\mathrm{xx}$, amb un punt evident de romanticisme, que s'apropen més a la imatge dels antiquaris col-leccionistes de l'època moderna a Europa que no pas a la dels arqueòlegs acadèmics, que arribaren a Catalunya sota el guiatge de Pere Bosch Gimpera durant la segona dècada del segle xx.

De fet, els paral-lelismes entre Sagarra i Rubio arriben fins i tot al destí final de les seves respectives col-leccions arqueològiques. Així, el 1925, set anys després de la seva mort, la vídua de Rubio, Dolores López, acceptà donar la col-lecció del seu marit a la secció arqueològica del Museu d'Art Decoratiu i Arqueològic, situat a la Ciutadella de Barcelona. Segons paraules de Serra Ràfols, la donació de Dolores López estava motivada pel "desig de enaltir la memòria de D. Joan Rubio de la Serna, al fer més coneguda la seva obra dipositant el fruit del seu treball en un museu públic" (Serra Ràfols 1926: 3 s.).

5. Biblioteca de Catalunya, Fons Ferran de Sagarra, Capsa 2, Lligall 40/2. 
Exactament aquell espai físic de la Ciutadella fou també el destí de la col-lecció arqueològica de Sagarra, amb la diferència que en aquest cas va ser el mateix Sagarra qui va fer el donatiu en vida seva, i no la seva vídua com a homenatge pòstum. Com veurem més endavant, el 1916, Sagarra, que ja havia abandonat les excavacions al Puig Castellar per dedicar-se exclusivament als estudis de sigil-lografia, procedí a la donació tant del jaciment arqueològic com de la seva col-lecció de materials a l'Institut d'Estudis Catalans que, al seu torn, optà per cedir les peces a la secció arqueològica del Museu d'Art Decoratiu i Arqueològic.

D'aquesta manera els museus privats de Sagarra i Rubio es reuniren finalment el 1925, una acció simbòlica que, d'alguna manera, ens serveix per tancar una etapa en la història de l'arqueologia a Catalunya. Sagarra, com Rubio, eren homes del segle xIx, la tasca arqueològica dels quals, encara que molt meritòria, quedà àmpliament superada per l'escola que Pere Bosch Gimpera estava creant des de la seva càtedra de la Universitat de Barcelona. Sagarra amb la seva donació demostrà ser perfectament conscient que el seu temps en l'arqueologia ja havia passat, que els nous arqueòlegs posseïen uns coneixements i aplicaven unes tècniques que ja no estaven al seu abast. En donar la seva colllecció, en desfer-se del seu museu, Sagarra admetia que el temps del arqueòlegs-col-leccionistes, dels diletants antiquaristes s'estava extingint.

\section{Les societats "arqueològiques" i les institucions públiques}

L'afició de Sagarra per l'arqueologia el va portar a entrar en contacte directe amb les principals societats i institucions catalanes d'aleshores més o menys relacionades amb aquesta activitat. Així, segons consta al seu expedient conservat a la Reial Acadèmia de Bones Lletres de Barcelona, Sagarra va pertànyer a un mínim de tres institucions catalanes directament relacionades amb l'arqueologia: soci de l'Asociación Artístico-Arqueológica de Barcelona (1878), soci corresponent de la Societat Arqueològica Tarraconense (1885) i membre de l'Associació Catalanista d'Excursions Científiques (1884). A aquestes cal afegir, per descomptat, la mateixa Reial Acadèmia de Bones Lletres, on ingressà el $1890,{ }^{6}$ la Real Academia de la Historia, de la qual va ser nomenat corresponent el novembre de $1888,{ }^{7}$ membre de la comissió del Museu de la Història $(1892)^{8}$ i de la Secció HistòricoArqueològica de l'Institut d'Estudis Catalans (1920).

Pel que fa a les tres primeres institucions esmentades, les més específicament relacionades amb l'arqueologia, val a dir que Sagarra va mantenir una desigual relació amb totes tres. Així, mentre que establí vincles estrets

6. La notícia del seu ingrés a l'Acadèmia va ser àmpliament recollida a la premsa (per exemple, La Dinastía 17/06/1890, p. 2; La Unión Católica 17/06/1890, p. 1).

7. On se li va encarregar la creació d'una secció sigil-logràfica dins del museu (La Dinastía 09/02/1892, p. 2; vegeu també La Dinastía 29/11/1888, p. 3).

8. La Vanguardia 12/02/1892, p. 3; La Dinastía 12/02/1892, p. 2 . amb l'Asociación Artístico-Arqueológica de Barcelona i amb l'Associació Catalanista d'Excursions Científiques, la seva presència i implicació amb la Tarraconense va ser més aviat testimonial.

L’Asociación Artístico-Arqueológica de Barcelona, fundada el 1877 per iniciativa de Josep Puiggarí i Llobet, historiador de l'art, arxiver i dibuixant barceloní, va ser una institució en origen amb una concepció de l'arqueologia bastant allunyada dels nostres criteris actuals. Els seus principals interessos estaven relacionats no amb les excavacions sinó amb el comerç i el col-leccionisme d'art antic. El seus òrgans d'expressió foren primer el Boletín i després la Revista de la Asociación Artístico-Arqueológica de Barcelona, de la qual es publicaren sis volums, entre 1896 i 1910. Amb el temps, i fins a la seva desaparició el 1913, l'associació evolucionà en el seu concepte d'arqueologia, apropant-se cada cop més a uns estàndards podríem dir-ne actuals, tot prioritzant la investigació i protecció del patrimoni artístic per damunt d'aquella primera vocació col-leccionista (Cortadella 2009).

Sagarra va ingressar-hi com a soci el 30 d'abril de 1878. Va ser nomenat vocal de la seva junta directiva en dues ocasions, el 20 de novembre de 1884 i el 6 de novembre de 1887. Al mateix temps, i més enllà de les tasques de gestió i de direcció, Sagarra també va fer servir l'associació per, de vegades, gestionar la seva col-lecció d'antiguitats. Així es desprèn, per exemple, d'una carta de 5 de març de 1888 que el secretari de l'associació, Ramon Soriano, envià als socis que, com Sagarra, eren propietaris de col-leccions arqueològiques. ${ }^{9}$ Segons s'informa al document, Soriano convidava Sagarra a cedir algunes peces de la seva col-lecció particular a l'associació, que s'encarregaria de les gestions corresponents per promoure'n l'exhibició a la mostra d'art retrospectiu celebrada dins del marc de l'Exposició Universal de Barcelona de 1888.

Pel que fa a la Societat Arqueològica Tarraconense, l'ingrés de Sagarra en aquesta institució com a soci corresponent es produí el 22 de febrer de 1885 . Juntament amb Sagarra aquell dia van ser nomenats també el seu oncle, l'historiador Ramon de Siscar i de Montoliu, el pintor Alfons Gelabert i Buxó, el metge Francesc Viñas Serra (qui el 1876 va publicar un treball sobre el material arqueològic trobat al Puig de les Ànimes, Caldes de Malavella) (Viñas 1876), l'arqueòleg, numismàtic i historiador Joaquim Botet i Sisó (qui, entre d'altres, va descobrir i excavar la necròpolis romana i la torre sepulcral dels Avellaners de Can Sala, Lloret de Mar) (Botet 1892) i l'escriptor i polític Josep Saderra i Mata (qui publicà un estudi sobre el santuari de la Verge del Tura, Olot) (Saderra 1905).

La Societat Arqueològica Tarraconense fou fundada el 1844, i va obtenir el títol de Reial el 1914 per concessió d'Alfons XIII. Entre els seus objectius primers destacava la voluntat de protegir i conservar el patrimoni material antic i medieval de la província de Tarragona, així com, mitjançant una decidida tasca pedagògica, estendre entre la població més jove

9. Carta de Ramon Soriano a Ferran de Sagarra, de 5 de març de 1888. Biblioteca de Catalunya, Fons Ferran de Sagarra, Capsa 2, Lligall 26. 
el gust per l'estudi de les antiguitats. ${ }^{10} \mathrm{El}$ seu òrgan d'expressió és el ja centenari Boletín Arqueológicol Butlletí Arqueològic, publicat per primer cop el 1901. El cert, però, és que les relacions de Sagarra amb la Societat van ser més testimonials que no pas efectives. Com a mínim així es desprèn tant de l'absència de notícies d'arxiu que evidenciün l'existència de contactes, com del fet que al volum commemoratiu del 150 è aniversari de la institució, el nom de Sagarra aparegui en una única ocasió, a la llista final dels socis corresponents de la institució (Ferrer / Dasca / Rovira 1994: 371).

Finalment, val la pena destacar els vincles, ara sí, estrets entre Sagarra i l'Associació Catalanista d'Excursions Científiques. Fundada el 1876, per descomptat tenia uns objectius lúdics, inherents a la tasca excursionista, però també s'interessà per l'arqueologia, dins d'un marc d'actuació caracteritzat per la voluntat de refer les bases històriques de la nació catalana. D'aquesta manera, des de l'Associació es promovia el coneixement del passat català mitjançant la visita a jaciments arqueològics. Però també es posà molt d'èmfasi en la necessitat de recuperar el patrimoni arqueològic i artístic català, per la qual cosa s'organitzaren cursos i s'editaren diverses publicacions que pretenien contribuir a l'assoliment d'aquest objectiu. El 1890 l'associació es fusionà amb la seva antiga escissió, l'Associació d'Excursions Catalanes, donant lloc al Centre Excursionista de Catalunya (Cortadella 1997).

Sagarra ingressà com a soci el $1884^{11}$ i s'implicà activament en la vida de l'Associació. Participà en la seva gestió, féu conferències, incrementà el seu patrimoni i organitzà "excursions" per als socis per conèixer la seva extraordinària col-lecció sigil-logràfica a la casa del carrer dels Mercaders de Barcelona. Sagarra s'integrà a la junta directiva de l'associació i arribà a exercir el càrrec de vicepresident el 1889. ${ }^{12}$ D'altra banda, implicat també en la seva tasca pedagògica, dictà un mínim de tres conferències entre 1887 i 1888 a la seu de l'entitat, situada al carrer Paradís 10, 2a, i sempre dedicades a qüestions de sigillografia. Així, tenim notícies d'una primera conferència dictada el 16 de maig de 1887 amb el títol de "Importància de la Sigil-lografia considerada com à ciència històrica"; ${ }^{13}$ una altra del 9 de desembre d'aquell mateix any, on Sagarra exposà les noves dades sigil-logràfiques obtingudes durant la seva estada de recerca a l'arxiu episcopal de Vic, ${ }^{14}$ i una darrera del 27 de gener de $1888,{ }^{15}$ de la qual fins $i$ tot es va publicar un resum a la premsa catalana. ${ }^{16} \mathrm{~A}$ més, l'any del seu ingrés,

10. Segons s'afirma a l'article primer del Reglamento general para el gobierno interior de la Sociedad Arqueológica Tarraconense, Tarragona 1845.

11. El seu ingrés, juntament amb el de Joan Casadó, Gaspar Rodés, Pere Grau, Manel de Larratea, Pío Freixa, Eusebi Vila, Pau Audouard, Lluís Sendra, Eusebi Soler i Josep Ixart, apareix recollit a L'Excursionista 66 (1884), p. 297.

12. L'Excursionista 134 (1889), p. 305; La Dinastía 16/12/1889, p. 2.

13. L'Excursionista 102 (1887), p. 25; La Dinastía 16/05/1887, p. 1.

14. La Dinastía 09/12/1887, p. 2-3.

15. La Dinastía $27 / 01 / 1888$, p. 1.

16. La Vanguardia $01 / 02 / 1888$ p. 2.
Sagarra donà als fons de l'entitat una col-lecció de 211 segells timbrats de diferents ajuntaments de Catalunya. ${ }^{17}$ Finalment, conservem també notícies al voltant de l'organització per part de l'Associació de visites a la col-lecció sigil-logràfica de Sagarra, ${ }^{18}$ per la qual es feien fins i tot sessions preparatòries d'introducció a l'esmentada col.lecció. ${ }^{19}$

El conjunt de dades recollides fins aquí ens ensenyen clarament com Sagarra era un nom del tot imprescindible quan es parlava d'arqueologia a la Catalunya de l'últim terç del segle XIX i principi del xx. Això explica també que les institucions públiques requerissin els seus serveis per tal de realitzar tasques d'assessorament en la seva política d'adquisició de peces arqueològiques.

Així s'especifica en un document de la Junta Tècnica del Museu de la Història, amb data de 27 de desembre de 1895. El document, signat per Carles Pirozzini i Josep Maria Nadal, comunica a Sagarra el seu nomenament, juntament amb Francesc Carreras Candi, per formar part d'una ponència encarregada de gestionar l'entrega a l'Ajuntament de Barcelona de tot un seguit de peces arqueològiques que estaven en mans de particulars. ${ }^{20}$ En aquesta mateixa línia Sagarra fou nomenat per l'Ajuntament de Barcelona vocal numerari de la Junta Tècnica dels Museus de Belles Arts, Arqueologia i Indústries Artístiques, el 2 d'agost de 1897. ${ }^{21}$ Com a membre de la Junta de Museus, participà activament en l'adquisició i gestió de peces artístiques $\mathrm{i}$ arqueològiques de Catalunya. Gràcies a l'estudi realitzat per Maria Josep Boronat podem reconstruir amb bastant detall la tasca de Sagarra, i d'altres membres de la societat civil catalana, relacionada amb aquest àmbit (Boronat 1999: 214, 248, 330, 405 ss.). Així, el 1906, juntament amb Josep Regent i Josep Puig i Cadafalch, Sagarra redactà un informe valorant els materials oferts a la Junta per l'antiquari Andreu Larraga. Aquell mateix any, Sagarra i Manuel Fuxà van ser designats per la Junta per gestionar la compra de l'anomenada Majestat d'Organyà, un crucifix de fusta policromada procedent d'aquella parròquia de l'Alt Urgell, avui conservat al Museu Nacional d'Art de Catalunya. El 1908, i amb motiu de l'obertura de la Sala del Rei D. Jaume del Museu d'Art Decoratiu i Arqueològic, Ferran de Sagarra, Emili Cabot i Josep Pijoan s'encarregaren de reunir

17. L'Excursionista 66 (1884), p. 304.

18. Un complet reportatge sobre una visita que tingué lloc a la fi de febrer de 1887 va ser publicat a L'Excursionista 101 (1887), p. 20 ss. Al butlletí de l'associació se succeeixen referències a d'altres visites (per exemple, L'Excursionista 114 (1888), p. 140). Posteriorment, quan ja l'Associació s'havia convertit en el Centre Excursionista de Catalunya, continuaren aquestes visites, tal com ho demostra la notícia publicada a $\mathrm{La}$ Vanguardia 18/06/1893, p. 2. Una completa ressenya d'aquella visita, encapçalada pel llavors president del centre, Francesc de Sales Maspons i Labrós, es va publicar al butlletí de l'entitat, amb el títol "Visita a las coleccions de D. Ferrán de Segarra [sic] y de Siscar" (Butlletí del Centre Excursionista de Catalunya 9 (1893), p. 99-100).

19. L'Excursionista 99 (1887), p. 1.

20. Biblioteca de Catalunya, Fons Ferran de Sagarra, Capsa 2, Lligall 26.

21. Biblioteca de Catalunya, Fons Ferran de Sagarra, Capsa 2, Lligall 26. 
els objectes que s'hi havien d'exposar. Finalment, el 1912 Sagarra va ser el responsable de negociar l'adquisició per a la Junta de diferents peces procedents del monestir de Sant Cugat.

\section{Les excavacions al Puig Castellar}

Malgrat tot el que hem dit fins ara, el cert és que si Sagarra mereix un lloc dins de la història dels pioners de l'arqueologia a Catalunya és essencialment per les excavacions arqueològiques que va portar a terme al jaciment ibèric del Puig Castellar.

La història de les excavacions de Sagarra al Puig Castellar és ja prou coneguda. És per això que el repàs que farem a continuació serà molt breu, destinat únicament a contextualitzar les reflexions que seguiran més endavant, i es basarà principalment en el testimoni ofert pel mateix Sagarra (Sagarra 1905a: 88 s.) i pel seu fill (Sagarra 1954: 320 s.).

Entre el patrimoni de la família Sagarra hi havia una gran finca, la Torre Balldovina, situada a Santa Coloma de Gramenet. Allà destacava la muntanya coneguda popularment amb el nom de Turó del Pollo, on se situa el poblat ibèric del Puig Castellar. La muntanya, coberta per un bosc de pins, era sovintejada pel mateix Sagarra qui, al llarg dels anys, havia notat l'existència en superfície del que en aquells moments identificava com a ceràmica romana. Incapaç de trobar referències escrites rellevants sobre la història més antiga del lloc, Sagarra optà per "fer parlar à la terra" i conèixer així quin era l'origen d'aquells materials (Sagarra 1905c: 234). El 1902 realitzà una primera intervenció sobre el terreny, fet que li permeté extreure més mostres ceràmiques, que comparà amb les troballes de Rubio de la Serna a Cabrera de Mar. Per la seva banda, Joan Palà, rector de Santa Coloma de Gramenet, aquell mateix any recollí més mostres de ceràmica, que ensenyà $i$ discutí amb Jaume Collell, canonge de Vic. ${ }^{22}$ Tant les seves pròpies troballes com les realitzades i comentades per aquells homes d'església empenyeren Sagarra a iniciar les excavacions l'agost de 1904, amb l'ajut d'alguns dels seus jornalers.

La durada exacta de les excavacions de Sagarra al Puig Castellar és difícil de determinar. A l'article on descriu les troballes únicament fa referència a la campanya d'agost-setembre de 1904. En canvi, a les memòries familiars, el seu fill parla de tres estius de treballs al Puig Castellar (1904-1906) (Sagarra 1954: 321). Per la seva banda, a la bibliografia especialitzada tampoc no existeix unanimitat, ja que trobem referències a una (1904) (De la Pinta / Río-Miranda 1981: 4), dues (1904-1905) (Sanmartí / Gili / Rigo / de la Pinta 1992: 48; Clavell / Manzano / Marín / Muñoz / Rico 2008: 8; Panosa 2012: 69), tres (1904-1906) (Serra 2005: 19) i, fins i tot, quatre campanyes (19041907) (Ferrer / Rigo 2003: 10). En un primer moment,

22. Jaume Collell i Bancells (Vic, 1846-1932). Sacerdot, escriptor i periodista. Malgrat que no es dedicà mai a l'arqueologia de camp, Collell era un dels intel-lectuals més actius del catalanisme de l'època (Costa 2003), la qual cosa explica que es recorregués a la seva persona també en qüestions relacionades amb la cultura material. l'opció de dues úniques campanyes semblava la més probable. Així ho indicava, per exemple, el testimoni de Josep Pijoan, qui afirmava que l'estiu de 1905 Sagarra va suspendre "los trabajos definitivamente". ${ }^{23}$ Ara, però, i gràcies a la informació registrada en un document conservat al Fons Sagarra de la Biblioteca de Catalunya, sabem que en realitat les campanyes continuaren com a mínim fins al 1908. ${ }^{24}$ L'esmentat document és una llista on es registra el pagament als treballadors que van participar en les excavacions realitzades al jaciment el setembre de 1908. Si suposem que entre 1904 i 1908 aquestes excavacions no es van interrompre (quelcom que no sabem del cert), llavors caldria parlar d'un total de cinc campanyes dirigides per Sagarra al Puig Castellar.

Durant les primeres campanyes Sagarra dirigí un equip format per un grup de 18-20 dels seus jornalers, que treballaven coordinats per un capatàs. Amb el temps, però, i a mesura que avançaven les excavacions, Sagarra reduí el nombre de treballadors fins a sis, ${ }^{25}$ als quals pagava tres pessetes per dia d'excavació. Aquesta reducció tan significativa testimonia l'evident descens en la intensitat del treball $i$ en l'interès de Sagarra pel jaciment, com ho demostra el fet que no publiqués ni una sola línia sobre les excavacions posteriors a 1904.

Els treballs arqueològics es concentraren al cim i al vessant meridional del turó, afectant una superfície total d'uns $1.000 \mathrm{~m}^{2}$. Entre les troballes realitzades i el material recuperat podem destacar diversos elements arquitectònics (un tram de la muralla i diverses estances), pedres de molí, estris per al treball del metall, utillatge d'os, eines i armes de ferro, abundant ceràmica (incloent importacions gregues), una col-lecció de com a mínim cinc cranis humans, etc.

En general, les excavacions de Sagarra van generar un interès considerable no només entre la comunitat científica, sinó que també tingueren un cert impacte social. Prova d'això la trobem a la visita que els periodistes de La Veu de Catalunya feren a Sagarra el setembre de 1904, a la seva residència de Santa Coloma de Gramenet, per tal d'obtenir dades de primera mà al voltant de les excavacions que llavors tot just s'acabaven d'iniciar, i així poder informar els seus lectors. ${ }^{26} \mathrm{~A}$ més, l'interès no es va limitar al moment sempre efervescent de la troballa, sinó que el jaciment va seguir generant atenció els anys següents i va convertir-se en una veritable referència per a la difusió de l'estudi de la prehistòria a Catalunya. Així ho demostra una notícia publicada a La Vanguardia, on s'informava que el dimarts 3 de març de 1908 s'havia organitzat una excursió per a la formació de mestres al jaciment. Val la pena reproduir aquí el breu text:

23. Pijoan 1906: 485 s.

24. Biblioteca de Catalunya, Fons Ferran de Sagarra, Capsa 2, Lligall 40/2.

25. Gràcies al document abans esmentat coneixem els seus noms: Leon Villagrasa, Jaume del Pericot, Juan Pastor, Domingo Aparicio, Patricio Nebot i Jaume Galobardas.

26. La Veu de Catalunya 13/09/1904, p. 1 s. 
Para el martes próximo se ha organizado una excursión de maestros y maestras á la estación prehistórica de Puig Castellar, término de Santa Coloma de Gramanet.

Cuantos deseen assistir se reunirán, á las cinco y media de la mañana, en la plaza de Urquinaona, delante de la Central de Correos.

Entre ida y vuelta se calculan 10 kilómetros en tranvía y 12 á pie.

Los excursionistas estarán de regreso en Barcelona á la una de la tarde. ${ }^{27}$

Com hem comentat abans, malgrat que Sagarra probablement va dirigir cinc campanyes d'excavació al jaciment, només publicà un únic article, presentant els resultats de la campanya de 1904, la primera que va portar a terme.

De fet, Sagarra sempre es va mostrar bastant reticent a publicar els seus treballs al Puig Castellar. Aquesta reticència de Sagarra s'aprecia clarament en l'esborrany d'una carta a l'escriptor Francesc Matheu. ${ }^{28}$ Malgrat que el text no porta data, probablement es va escriure a final de l'estiu o principi de la tardor de 1904. Com podem veure tot seguit, Sagarra rebutjava amablement l'oferta de Matheu de publicar un article sobre la primera campanya d'excavacions al Puig Castellar a la revista La Ilustració Catalana que dirigia el mateix Matheu. Els motius donats per Sagarra eren les dificultats a les quals havia de fer front en la interpretació de les troballes, unes dificultats que l'obligaven a mostrar-se prudent abans de donar a conèixer els resultats:

\section{Sr. D. Francesch Matheu.}

Molt Sr. Meu y distinguit amich:

He rebut sa carta del 24 corrent y [...] que li agraeich la oferta que'em fa de las planas de la Ilustració que vosté ab tant acert y patriotisme dirigeix pera escriure quelcom referent a la troballa de Puig Castellar.

[...] crech que per ara considero convenient no dirne gran cosa ó millor res perque hi ha molts punts foscos pera aclarir y molt pera estudiar y crech no podrá ferse fins que ulteriors excavacions posin ben de manifest la naturalesa de aytal troballa.

Aleshoras podrem parlarne ab ple coneixement de causa y tindré un verdader plaer en que la Ilustració Catalana [...] y'ns posarem d'acord ab vosté per si convé reproduir alguns obgectes dels que vagin apareixent en el curs de las excavacions.

Reiterantli las mes corals merces pel seu oferiment quedo com sempre de voste afm.

Curiosament, molt poc temps després apareixia publicat al Boletín de la Real Academia de Buenas Letras de Barcelona l'únic article de Sagarra sobre les excavacions al Puig Castellar. Aquest fet permet suposar la possibilitat que en realitat Sagarra hauria rebutjat la proposta de Matheu no per les dificultats interpretatives que li plantejava el jaciment sinó perquè hauria preferit publicar el seu treball dins de la revista d'una institució a la qual pertanyia des de 1890 i amb la qual col-laborava amb freqüència.

27. La Vanguardia $01 / 03 / 1908$, p. 2 .

28. Biblioteca de Catalunya, Fons Ferran de Sagarra, Capsa 2, Lligall 40/2.
En qualsevol cas, el que és clar és que Sagarra va actuar de manera molt diferent a com ho havia fet Rubio de la Serna durant les seves excavacions a la necròpolis de Cabrera de Mar. Si Rubio va publicar un total de sis articles sobre les excavacions a Cabrera (Rubio 1884, 1886, 1887, 1888a, 1888b, 1889), Sagarra es limità a escriure el breu article que ja hem esmentat. Segons el meu parer, podem plantejar dues possibilitats que no són excloents per entendre aquesta situació. D’una banda, efectivament, és possible que Sagarra, davant les dificultats que presentaven les excavacions, adoptés una postura de prudència i decidís limitar les seves publicacions al respecte. De l'altra, cal tenir en compte que Sagarra probablement preferí prioritzar els treballs sobre sigillografia, la seva vocació principal, per davant de les excavacions del Puig Castellar. En aquest sentit és important recordar que el 1908, quan va tenir lloc l'última campanya al Puig Castellar, Sagarra publicava dos articles de contingut sigil-logràfic (Sagarra 1908a i b). Durant el període 1909-1912 publicà quatre nous articles d'aquesta mateixa temàtica, a raó d'un per any (Sagarra 1909, 1910, 1911, 1912). Finalment, el 1916 apareixia el primer volum de la seva Sigil.lografia Catalana. Aquest conjunt de publicacions consecutives ens permet imaginar un Sagarra molt més ocupat en la seva recerca sobre els segells catalans que no pas en les excavacions del Puig Castellar.

Aquestes dues raons ens ajuden a entendre per què després del seu article de 1905 Sagarra no va publicar ni una sola línia sobre les campanyes aqueològiques efectuades durant el període 1905-1908.

Pel que fa al contingut d'aquella única publicació sobre el Puig Castellar, val a dir que Sagarra dedicava la major part de l'espai a oferir minucioses descripcions dels diferents elements exhumats. En canvi, la part reservada a la interpretació històrica és quantitativament limitada, per la qual cosa l'interès del relat queda inevitablement focalitzat en l'estudi dels objectes.

Les interpretacions arqueològiques de Sagarra es caracteritzen per un rigor metodològic prou destacable. Un bon exemple d'això el trobem en la seva anàlisi d'una de les troballes més famoses del Puig Castellar. Ens estem referint al crani enclavat que actualment es conserva al Museu d'Arqueologia de Catalunya (MAC-BCN 39986). Sagarra descriu amb precisió forense les característiques antropològiques del crani (forma, índex cefàlic, prognatisme, sutures cranials, etc.). De manera similar procedeix amb el clau (mides, material, forma original, etc.) (Sagarra 1905a: 90 s.). Finalment, a l'hora d'abordar la interpretació relaciona la troballa amb el famós episodi de Diodor de Sicília, on l'autor clàssic es refereix al costum celta dels caps tallats dels enemics exposats com a trofeu de guerra (Sagarra 1905c: 237). Convé notar que aquesta idea encara avui és acceptada com la més versemblant per tal d'interpretar els cranis enclavats documentats no només al Puig Castellar, sinó també a Ullastret (Rovira 1998; Sanmartí / Santacana 2005: 165; Rovira / Codina 2015; dif. Gracia 2015).

Amb tot, Sagarra, conscient de les seves limitacions en matèria d'arqueologia de camp, mirà de consultar 
amb alguns especialistes per conèixer la seva opinió sobre les troballes i aclarir així alguns dubtes. El problema, però, és que en aquells moments, abans de la institucionalització de l'arqueologia a Catalunya mitjançant la creació de l'Institut d'Estudis Catalans (1907) i el Servei d'Investigacions Arqueològiques (1915), les possibilitats que tenia Sagarra de trobar veritables arqueòlegs amb qui discutir sobre les seves excavacions eren força limitades. Finalment, va recórrer als amics més propers, com el ja esmentat Norbert Font i Sagué, ${ }^{29}$ qui, després de visitar Sagarra i analitzar directament els materials, arribà a la conclusió que el Puig Castellar era un jaciment exclusivament romà. ${ }^{30}$

La proposta de Font ens permet introduir ara la qüestió de la datació del Puig Castellar, un dels problemes que més dubtes va plantejar a Sagarra. Discrepant del seu amic Font, Sagarra va identificar correctament el caràcter ibèric $i$, per tant, preromà del jaciment, però li atribuí una fase d'ocupació molt àmplia. Així, en funció dels materials recuperats i de les característiques dels cranis (als quals atribuïa trets neandertaloides), Sagarra arribà a la conclusió que l'ocupació del jaciment s'estengué des del Neolític fins al període ibèric, donant lloc al que molt gràficament va descriure com una "confusió de civilisacions” (Sagarra 1905c: 236). Si bé aquesta cronologia àmplia en un primer moment va ser acceptada per alguns autors, ${ }^{31}$ ràpidament va ser corregida per Bosch Gimpera, qui negà l'existència d'aquesta fase neolítica i establí el caràcter únicament ibèric del jaciment (Bosch Gimpera 1919: 128 s.).

Finalment, també cal destacar, malgrat que no era un arqueòleg professional, el sorprenent coneixement que tenia Sagarra de la literatura arqueològica (i epigràfica) de l'època, tant en l'àmbit català com internacional (sobretot de tradició francòfona). D'aquesta manera, les seves descripcions sovint van acompanyades de citacions als treballs d'autors com Rubio de la Serna, Josep Pella i Forgas, José Villaamil y Castro, José Joaquín Landerer, Juan Vilanova y Piera, Manuel de Góngora y Martínez, els germans Louis i Henri Siret, Emil Hübner, Émile Cartailhac, Gabriel de Mortillet i Victor Place, entre d'altres, autors que sembla conèixer de primera mà en funció de les citacions bibliogràfiques que fa i el resum dels continguts que comenta. Aquest domini de la bibliografia resulta especialment meritori tenint en compte que l'arqueologia no era el seu àmbit principal d'estudi, cosa que denota la profunditat de la seva inquietud intel-lectual, així com, en certa mesura, la seva ben coneguda passió bibliòfila (Serra 2005: 13).

En general, podem considerar que la historiografia ha valorat prou positivament la tasca pionera de Sagarra, destacant de manera reiterada la qualitat

29. Norbert Font i Sagué (Barcelona, 1874-1910). Intel-lectual i científic polifacètic (historiador de la ciència, geòleg, espeleòleg, etc.), entrà en contacte directe amb l'arqueologia sobretot de resultes de la seva tasca espeleològica i excursionista (Martí 2003).

30. La Veu de Catalunya 23/09/1904, p. 2.

31. Per exemple, Puig i Cadafalch definia el Puig Castellar com una estació de "tradició neolítica" (Puig i Cadafalch / de Falguera / Goday 1909: 11). i quantitat de les seves troballes, així com la seva intuïció a l'hora de realitzar les excavacions. Tenint en compte el moment en el qual es van portar a terme els treballs de camp i el fet que Sagarra no fos un arqueòleg professional, els diferents autors al llarg dels anys s'han abstingut de fer valoracions negatives sobre els seus mètodes d'excavació. Ans al contrari, alguns d'ells, com Agustí Duran i Sanpere, consideraren que els treballs foren metodològicament impecables en el seu moment, a l'alçada de les aportacions realitzades, per exemple, pels germans Siret (Duran i Sanpere 1953: 315). Amb tot, el testimoni més elogiós ens l'ofereix el seu amic Josep Pijoan, qui de manera molt eloqüent escrivia: "un propietario inteligente y entusiasta como don Fernando de Sagarra, quien sin reparar en sacrificios ni perdonar gastos, ha ido exhumando una cantidad extraordinaria de objetos y noticias ya definitivamente reconquistados para la ciencia" (Pijoan 1906: 484). ${ }^{32}$ Pere Bosch Gimpera va ser, sens dubte, molt menys elogiós. Ja hem comentat que en una de les seves primeres aproximacions a l'estudi de Puig Castellar, Bosch Gimpera corregia Sagarra, sense citar-lo, tot descartant la idea apuntada per aquest (Sagarra 1905b: 161 i 1905c: 234 s.) al voltant de la possible existència de nivells neolítics al jaciment (Bosch Gimpera 1919: 128 s.). Amb tot, pocs anys després, Bosch Gimpera ometia tota crítica i acceptava com a "correctes" bona part de les propostes arqueològiques de Sagarra (Bosch Gimpera 1923: 594 n. 1). Per la seva banda, i en la mateixa línia que el seu mestre, Lluís Pericot va qualificar de "notable" la feina feta per Sagarra al Puig Castellar (Pericot 1953: 306 s.). Finalment, Serra Ràfols es limità a reconèixer el paper de Sagarra com a descobridor del jaciment, sense fer cap mena de valoració al voltant de la seva tasca (Serra Ràfols 1942: 85). Més recentment, una monografia sobre els orígens dels assentaments humans a l'àrea de Santa Coloma de Gramenet reconeixia el valor i la qualitat del treball de Sagarra "si hom té en compte la seva data” (Sanmartí / Gili / Rigo / de la Pinta 1992: 48).

Una nota lleugerament discordant ens la dóna Eduard Ripoll, qui celebrava obertament que els treballs de Sagarra es limitessin a una part i no a la totalitat del jaciment, fet que va permetre que posteriors intervencions, amb millors tècniques $\mathrm{i}$ una preparació més adequada, estudiessin sectors verges del Puig Castellar (Ripoll 1981: 4).

És ben cert, però, que recentment es pot constatar una tímida proliferació de crítiques molt puntuals envers el treball de Sagarra. En aquest sentit podem situar les lamentacions de Moncunill i Morell per la poca cura amb la qual Sagarra va fer l'inventari d'objectes de Puig Castellar, un fet que, afirmen les autores, ha dificultat molt poder determinar, per exemple, el lloc del jaciment on es va trobar la inscripció sobre plom núm. 36979 (Moncunill / Morell 2008: 245). També recentment Joan Sanmartí apuntava que va ser un article de Serra Ràfols de 1942 el primer lloc on es van publicar en condicions els materials del Puig Castellar, afirmació que, em sembla, deixa entreveure

32. Sobre l'amistat entre Sagarra i Pijoan vegeu Sagarra 1954: 322 
una crítica a les publicacions prèvies, incloses les de Sagarra (Sanmartí 2013: 45).

En general, podríem concloure l'existència d'una certa evolució en la valoració de la tasca arqueològica de Sagarra. Així, entre aquells autors que el van conèixer $\mathrm{o}$, com a mínim, van ser coetanis seus es donà una certa tendència a l'hagiografia (Pijoan, Duran i Sanpere), alhora que es reconeixien i valoraven els "mèrits arqueològics" d'algú que en realitat no deixava de ser un aficionat a la matèria (Bosch Gimpera, Pericot). A mesura que ha passat el temps, però, l'aproximació a la figura de Sagarra ha estat més equilibrada, s'ha reconegut en la justa mesura el seu paper pioner en l'arqueologia catalana però s'han destacat també algunes llacunes, segurament inevitables, en els seus treballs al Puig Castellar.

\section{El llarg procés de donació de Puig Castellar a l'Institut d'Estudis Catalans}

La donació del Puig Castellar per part de Sagarra a l'Institut d'Estudis Catalans (IEC) és un dels elements més comentats i celebrats a la bibliografia, i també un dels més confusos, sobretot pel que fa a la data concreta de la donació. En aquest sentit veiem com les xifres varien entre 1915 (Ripoll 1981: 4), 1917 (Martínez / Vicente 1966: 12; Gutiérrez 1987: 3; Sanmartí / Gili / Rigo / de la Pinta 1992: 48) i 1919 (Ferrer / Rigo 2003: 10; Clavell / Manzano / Marín / Muñoz / Rico 2008: 9; Panosa 2012: 69). Aquest ball de dades de ben segur s'explica per la complexitat en el procés de donació. Un repàs a les actes de les reunions de la Secció Històrico-Arqueològica de l'IEC ${ }^{33}$ ens ensenya amb cert detall les dificultats associades a aquest procés.

La primera vegada que s'esmenta la donació va ser en una reunió de 30 d'octubre de 1916. Allà s'informava que com a contrapartida i mostra d'agraïment, la Secció Històrico-Arqueològica de l'IEC regalaria a Sagarra totes les publicacions de la secció que li faltessin. ${ }^{34}$ El 5 de febrer de 1917 quedava clar que la donació encara no s'havia fet efectiva. L'eminent jurista i historiador del dret Guillem M. de Brocà estava fent gestions davant el Registre de la Propietat per tal d'agilitzar els tràmits. El mateix Brocà, Joaquim Miret i el notari Antoni Par eren els encarregats d'ultimar amb Sagarra els detalls de la donació. ${ }^{35}$ Una setmana més tard Brocà informava

33. Actes que es poden consultar a l'arxiu digital de l'IEC (http://arxiudigital.iec.cat/adiec/).

34. "S'acorda donar al Sr. Sagarra totes les publicacions de la Secció que li faltin com a testimoni d'agraiment pel donatiu que ha fet dels obgectes trobats a Puig Castellar en les seves excavacions i la cessió que ha fet a l'Institut del camp on es troba l'estació" (Acta de la reunió de la Secció HistòricoArqueològica de l'IEC de 30 d'octubre de 1916).

35. "El Sr. Puig dóna compte de que el Sr. Brocà li ha comunicat que en el Registre de la Propietat estàn disposats a donar tota mena de facilitats per a inscriure a nom de l'Institut qualsevol propietat que aquest adquireixi per compra, donació, etc. El Sr. Miret queda autoritzat per a parlar amb el Sr. Brocà i el notari senyor Par per a ultimar la cessió que fa a l'Institut el Sr. Sagarra de la seva propietat a Puig Castellar" (Acta de la reunió de la Secció Històrico-Arqueològica de l'IEC de 5 de febrer de 1917). que no s'havia pogut avançar en les gestions pel fet que Sagarra estava malalt. ${ }^{36}$ El 18 de juny de 1917 Brocà comentà que per poder fer l'escriptura de propietat feien falta uns documents (no s'especifica quins) que estaven en possessió de Ramon d'Abadal. Puig i Cadafalch es comprometia a obtenir aquests documents. ${ }^{37} \mathrm{El} 2$ de juliol d'aquell mateix any la situació continuava aturada ja que encara no s'havien pogut obtenir els papers que estaven en mans d'Abadal..$^{38}$ El 17 de desembre de 1917 Brocà informà de l'existència d'una hipoteca de l'Hogar Español sobre els terrenys del Puig Castellar. Malgrat tot, afirmava, això no seria un obstacle per a la investigació arqueològica del jaciment. ${ }^{39}$ El 27 de maig de 1918, és a dir, més d'un any i mig després de la primera notícia al voltant de la donació, Brocà reconeixia que aquesta estava pendent de formalitzar-se perquè d'Abadal encara no havia fet entrega dels documents que se li requerien. ${ }^{40}$ El 17 d'abril de 1919 és la primera vegada que s'esmenta la qüestió de la donació després de la mort de Brocà, qui fins aleshores havia estat l'encarregat de portar les gestions. Tenint en compte les noves circumstàncies s'acordà reprendre el procés, encarregant a Ramon d'Alòs-Moner, en substitució de Brocà, que activés les gestions necessàries a tal fi. ${ }^{41}$ El 12 de febrer de 1920 la situació semblava finalment desencallada. En aquest sentit, Sagarra va informar el ple de la Secció Històrico-Arqueològica de l'IEC que per fi es podia signar davant del notari Antoni Par l'escriptura de la cessió del jaciment. És molt interessant destacar aquí la voluntat de Sagarra,

36. "El Sr. Brocà indica que havent estat malalt aquests ultims dies el Sr. Sagarra no s'ha pogut ultimar la cessió que dit Sr. fa a l'Institut de les terres de Puig Castellar" (Acta de la reunió de la Secció Històrico-Arqueològica de l'IEC de 12 de febrer de 1917).

37. "El Sr. Brocà exposa els treballs que ha fet per deixar resolta la cessió de les terres del Puig Castellar que fa el Sr. Sagarra a l'Institut. Falta per enllestir-la la presentació al notari d'uns documents que té D. Ramón d'Abadal. El Sr. Puig parlarà amb el Sr. Abadal perque faciliti aquests documents" (Acta de la reunió de la Secció Històrico-Arqueològica de l'IEC de 18 de juny de 1917).

38. "El Sr. Brocà exposa les gestions que ha fet per resoldre ràpidament la donació de Puig Castellar que fa a la Secció el Sr. Sagarra. No s'han pogut encara obtenir els documents que té el Sr. Abadal i que precisen per a fer l'escriptura" (Acta de la reunió de la Secció Històrico-Arqueològica de l'IEC de 2 de juliol de 1917).

39. "El Sr. Brocà, tractant de la donació d'alguns terrenys de Puig Castellar, que fa a la Secció el Sr. Sagarra, anuncia que subsistirà damunt d'ells la hipoteca de l'Hogar Espanyol; però que això és secundari, sobre tot tenint en compte que aquest permetrà que s'hi facin les excavacions oportunes" (Acta de la reunió de la Secció Històrico-Arqueològica de l'IEC de 17 de desembre de 1917).

40. "El Sr. Brocà exposa les gestions fetes per a formalitzar la donació del Puig Castellar, que no s'ha pogut encara resoldre per estar entretinguts els documents necessaris en poder del senyor Abadal" (Acta de la reunió de la Secció HistòricoArqueològica de l'IEC de 27 de maig de 1918).

41. "S'acorda aixi mateix activar les gestions per ultimar la adquisició de Puig Castellar que el Sr. Sagarra cedeix a l'Institut, quedant encarregat el Sr. Alòs de parlar-ne amb dit senyor" (Acta de la reunió de 17 d'abril de 1919 de la Secció Històrico-Arqueològica de l'IEC). En aquest sentit cal notar que en la correspondència entre Sagarra i d'Alòs que es conserva a l'Arxiu de l'IEC (19 cartes i notes), no hi ha cap referència al procés de donació del Puig Castellar. 
qui especificava que, sota cap concepte, el jaciment podia "passar a propietat de l'Estat". ${ }^{42}$ Amb aquesta afirmació Sagarra dóna una mostra evident del seu ferm compromís amb el catalanisme polític. Nascut en una família de tradició carlina, aviat evolucionà cap al catalanisme conservador de la Lliga. El 1905, any en què dirigí la segona campanya al Puig Castellar, també fou escollit regidor pel districte IV de Barcelona. Amb tot, als anys vint, desenganyat per la col-laboració entre Francesc Cambó i Antonio Maura, ingressà a Acció Catalana, i va ser escollit diputat per Barcelona el 1923. Finalment, però, es reincorporà a la Lliga i tornà a ser escollit regidor per Barcelona el 12 d'abril de 1931. Una conseqüència directa de la seva militància catalanista van ser les seves donacions de part del seu patrimoni bibliogràfic, sigil-logràfic i arqueològic a diverses institucions com la Biblioteca de Catalunya, l'Arxiu Històric de Barcelona, el Museu Arqueològic, a banda, és clar, del mateix IEC (Serra 2005: 43 s.). Aquesta preocupació de Sagarra per conservar el patrimoni arqueològic que li era més proper situant-lo sota la tutela d'institucions catalanes explica que molts anys després el seu fill es referís al "catalanisme arqueològic" del seu pare (Sagarra 1954: 162).

La penúltima notícia relacionada amb el procés de donació la trobem l'11 de març de 1920. Aquell dia va ser Ferran Valls i Taberner l'encarregat de comunicar al ple que finalment s'havien pogut resoldre totes les dificultats per poder dur a terme la cessió. ${ }^{43}$ Això permetè a l'Institut promoure unes noves excavacions al jaciment (concretament al sector nord-occidental) entre 1922 i 1925, sota la direcció de Josep Colominas primer i de Serra Ràfols després. Amb tot, i per causes que desconeixem, no fou fins al 30 de març de 1932 (més de 15 anys després de la primera notícia al respecte) que Sagarra formalitzà en escriptura davant del notari Par la donació a l'IEC dels terrenys on es troba el Puig Castellar. ${ }^{44}$

És, sens dubte, aquesta enorme dilació en el procés de donació la que explica les evidents dificultats identificades a la historiografia per poder determinar amb exactitud la data concreta de la donació del Puig Castellar per part de Sagarra a l'IEC. Un estudi aprofundit de les circumstàncies legals i personals que envoltaren la donació (estudi que supera les nostres

42. "El Sr. Sagarra indica que quant la Secció ho cregui convenient es pot procedir a fer l'escripture de cessió a l'Institut de les terres de Puig Castellar, sense altre condició que la de no poder passar a propietat de l'Estat. S'acorda que el mateix Sr. Segarra [sic] fassi les gestions necessàries amb el notari Sr. Par per a deixar enllestida aquesta qüestió" (Acta de la reunió de la Secció Històrico-Arqueològica de l'IEC de 12 de febrer de 1920).

43. "El Sr. Valls exposa que ha visitat al notari Sr. Par per a formalitzar la donació de Puig Castellar feta pel Sr. Segarra [sic]. Han quedat resoltes totes les dificultats $\mathrm{i}$ es podrà tot seguit procedir a redactar l'escriptura" (Acta de la reunió de la Secció Històrico-Arqueològica de l'IEC de 11 de març de 1920).

44. "A propòsit d'aquesta qüestió i a instàncies del Sr. Sagarra es decideix formalitzar l'escriptura de donació del dit poblat a l'Institut per part del Sr. Sagarra i ell mateix queda encarregat de gestionar aquest afer amb el notari Sr. Par" (Acta de la reunió de la Secció Històrico-Arqueològica de l'IEC de 30 de març de 1932). capacitats) de ben segur que ens permetria entendre millor les causes últimes que expliquen aquests gairebé setze anys de procés veritablement kafkià.

\section{Conclusions}

Volem aprofitar aquestes darreres línies per ordenar les principals informacions i interpretacions que hem exposat fins ara. En aquest sentit considerem que la recepció de l'obra de Sagarra, des de la seva mort fins a l'actualitat, es pot resumir en quatre paraules: hagiografia, respecte, confinament, oblit. Anem per parts.

Hagiogràfica va ser, com dèiem, l'actitud demostrada per bona part dels seus coetanis, que feren ús d'encesos elogis per referir-se i valorar la seva obra, incloent la seva obra arqueològica. Més enllà de determinades exageracions (com la comparació amb els germans Siret), avui ben evidents, aquesta actitud, més que reflectir els seus mèrits arqueològics, en realitat és una bona mostra de la notable dimensió social i cultural que adquirí Sagarra a la Catalunya del primer terç del segle xx.

Respecte és el que van mostrar els primers professionals de l'arqueologia a Catalunya. Malgrat que autors com Bosch Gimpera o Pericot dominaven una tècnica arqueològica i posseïen uns coneixements acadèmics que superaven amb escreix els de Sagarra, van tenir la generositat intel-lectual suficient per valorar la figura de Sagarra no des de la perspectiva de l'arqueòleg professional sinó de l'historiador de l'arqueologia, capaç de reconèixer els mèrits d'una tasca pionera, més enllà de determinats dèficits inevitables.

Confinament. A mesura que ens allunyem de la data de la seva mort i desapareixen els seus contemporanis, la figura de Sagarra es va esvaint en la literatura arqueològica. La immensa majoria de les referències a la seva persona i a la seva tasca queda reclosa als estudis monogràfics sobre el Puig Castellar, on resulta inevitable referir-se al descobridor propietari del jaciment. Fora d'aquests estrets marges predomina l'oblit.

Oblit que es constata en algunes síntesis (no totes) i diccionaris d'història de l'arqueologia, on simplement no s'esmenta Sagarra entre la generació de pioners prèvia a la institucionalització de l'arqueologia a Catalunya. Són diversos factors els que poden explicar aquest oblit. Així, és clar que Sagarra, que romania al marge del món estrictament acadèmic de la universitat, no va crear cap mena d'escola arqueològica, per la qual cosa cap deixeble o seguidor no va reivindicar el seu llegat. D'altra banda, és cert que aviat les seves interpretacions al voltant del Puig Castellar es van veure superades per les realitzades per autors com Bosch Gimpera o, sobretot, Serra Ràfols, i per aquest motiu la citació dels seus treballs va ser prescindible. Així mateix, la magnitud de les seves aportacions en el camp de la sigil-lografia, en certa manera ha empetitit (i, a vegades, amagat) la seva tasca arqueològica, que el mateix Sagarra, és veritat, sempre va considerar secundària, i fins i tot esporàdica, dins dels seus interessos de recerca. Finalment, cal recordar que Sagarra fou un dels últims representants d'un món dominat per antiquaris 
i aficionats que s'extingia sense remei, per donar pas al sorgiment d'una veritable arqueologia catalana creada seguint els estàndards científics internacionals a l'estela de Bosch Gimpera.

Malgrat totes aquestes consideracions, la relació de Sagarra amb l'arqueologia va ser prou original i rellevant per ser adequadament recordada dins d'una panoràmica global de la història de la disciplina a casa nostra. En aquest sentit convé destacar dos punts bàsics: la seva convicció al voltant de la necessitat de les excavacions arqueològiques per suplir l'absència de fonts escrites, i la seva aposta per garantir l'estudi i la gestió del patrimoni arqueològic per part de les institucions catalanes.

De Sagarra cal destacar la seva convicció al voltant de la importància de l'excavació arqueològica com a font imprescindible per a la reconstrucció de la prehistòria i la història antiga de Catalunya. Sagarra era plenament conscient de quelcom que ara ens pot semblar obvi però que a la darreria del segle XIX i principi del Xx no ho era tant: les fonts clàssiques $\mathrm{i}$ els arxius no eren en absolut suficients per arribar a conèixer i reconstruir la història més antiga de Catalunya. Per aquest motiu, en el cas del Puig Castellar, sentí la necessitat de "fer parlar à la terra", és a dir, de recórrer a l'arqueologia de camp, ja que aquesta era l'única manera d'albirar el passat d'un assentament la història del qual es perdia en un temps massa remot per trobar-lo als arxius.

I de Sagarra també cal destacar el seu "patriotisme arqueològic", la seva convicció que el patrimoni material del nostre passat havia de ser estudiat i gestionat des de Catalunya, sense cap mena d'ingerència estatal, ja que aquesta era l'única forma de garantir-ne la salvaguarda. El Puig Castellar havia d'estar en mans de l'IEC i mai de cap institució depenent del govern de Madrid, perquè tenia la ferma convicció que "l'Estat Espanyol ens tracta pitjor que una colònia" (citat a Serra 2005: 45), també en matèria patrimonial. Tal com reconeixia Eva Serra (Serra 2005: 50), amb la seva donació, amb les seves donacions, Sagarra contribuí a posar un fragment del patrimoni històric del país al servei del catalanisme que representaven institucions com l'IEC.

Jordi Vidal

Departament de Ciències de l'Antiguitat i de l'Edat Mitjana Universitat Autònoma de Barcelona 08193 Bellaterra jordi.vidal.palomino@uab.cat

Rebut: 01-07-2015 Acceptat: 15-02-2016

\section{Bibliografia}

Anònim (1893). Visita a las coleccions de D. Ferrán de Segarra y de Siscar. Butlletí del Centre Excursionista de Catalunya, vol. 3, 9: 99-100.

Barral, X. (1989). L'arqueologia a Catalunya. Destino. Barcelona.

Boronat, M. J. (1999). La política d'adquisicions de la Junta de Museus 1890-1923. Publicacions de l'Abadia de Montserrat. Barcelona.

Bosch Gimpera, P. (1919). Prehistória Catalana. Enciclopèdia Catalana. Barcelona.

Bosch Gimpera, P. (1923). El donatiu de Puig Castellar, per D. Ferran de Sagarra, a l'Institut d'Estudis Catalans. Anuari de l'Institut d'Estudis Catalans. Secció HistòricoArqueològica, 1915-1920, 6: 593-595.

Botet, J. (1892). Monumento sepulcral romano en Lloret de Mar. Revista de Gerona, 16: 1-12.

Clavell, M. / Manzano, A. / Marín, S. / Muñoz, J. L. / Rico, M. (2008). Puig Castellar, Santa Coloma de Gramenet. Museu d'Arqueologia de Catalunya. Barcelona.
Cortadella, J. (1997). La investigación arqueológica en las asociaciones excursionistas catalanas (1878-1915). A: G. Mora i M. DíAz-Andreu (eds.). La cristalización del pasado. Universidad de Málaga. Màlaga: 273-285.

Cortadella, J. (2004). Juan Rubio de la Serna de Falces y Pelegero. Zona Arqueológica, 3: 169-173.

Cortadella, J. (2009). Asociación Artístico-Arqueológica Barcelonesa (AAAB). A: M. Díaz-Andreu / G. Mora I J. Cortadella (eds.). Diccionario Histórico de la Arqueología en España. Marcial Pons. Madrid: 99-100.

Costa, O. (2003). Collell i Bancells, Jaume. A: A. SIMÓN (dir.). Diccionari d'Historiografia Catalana. Enciclopèdia Catalana. Barcelona: 354-355.

De la Pinta, J. L. / Río-Miranda, J. (1981). El poblado layetano de Puig Castellar, Sta. Coloma de Gramenet (Barcelona). Museo Municipal "Puig Castellar”. Santa Coloma de Gramenet.

Díaz-Andreu, M. / Mora, G. / Cortadella, J. (eds.) (2009). Diccionario Histórico de la Arqueología en España. Marcial Pons. Madrid. 
DURAN I SANPERE, A. (1953). La arqueología y la historia del arte en la Real Academia de Buenas Letras. Boletín de la Real Academia de Buenas Letras de Barcelona, 25: 309-326.

Espino, A. (2003). Sagarra i de Siscar, Ferran de. A: A. Simón (dir.). Diccionari d'Historiografia Catalana. Enciclopèdia Catalana. Barcelona: 1047-1048.

Ferrer, C. / Rigo, A. (2003). Puig Castellar. Els ibers a Santa Coloma de Gramenet. 5 anys d'intervenció arqueològica (1998-2002). Museu Torre Balldovina. Barcelona.

Ferrer, M. A. / Dasca, A. / Rovira, J. (1994). CL anys de la Reial Societat Arqueològica Tarraconense. Reial Societat Arqueològica Tarraconense. Tarragona.

Gracia, F. (2015). Cabezas cortadas y rituales guerreros en la Protohistoria del Nordeste Peninsular. A: J. VIDAL / B. Antela (eds.). Guerra y religión en el mundo antiguo. Pórtico. Saragossa: 25-110.

Gracia, F. / Cortadella, J. (2007). La institucionalización de la arqueología en Cataluña: El Servei d'Investigacions Arqueològiques del Institut d'Estudis Catalans. A: M. Belén / J. Beltrán (eds.). Las Instituciones en el origen y desarrollo de la arqueología en España. Universidad de Sevilla. Sevilla: 257-321.

Gutiérrez, M. L. (1987). Puig Castellar, poblat laietà. Els ibers. Barcelona.

MARc-7 (1986). El procés de consolidació de l'arqueologia catalana. L'Avenç, 90: 55-61.

Martí, M. A. (2003). Font i Sagué, Norbert. A: A. Simón (dir.). Diccionari d'Historiografia Catalana. Enciclopèdia Catalana. Barcelona: 484-485.

Martínez, A. / Vicente, J. (1966). El poblat ibèric de Puig Castellar. Excavacions dels anys 1954-1958. Institut d'Estudis Catalans. Barcelona.

Moncunill, N. / Morell, N. (2008). Reexcavando en los museos: novedades epigráficas en soportes de plomo. Paleohispanica, 8: 243-255.

Nicolau d'Olwer, L. (1958). Caliu. Records de mestres $i$ amics. Institut Català de Cultura. Mèxic.

Panosa, M. I. (2012). Els ibers del Vallès Oriental. Publicacions de l'Abadia de Montserrat. Barcelona.

Pericot, L. (1953). La prehistòria en la Real Academia de Buenas Letras. Boletín de la Real Academia de Buenas Letras de Barcelona, 25: 305-307.

PijoAn, J. (1906). Una estación pre-romana en Cataluña. Hojas Selectas, 54: 483-492.

Puig i Cadafalch, J. / de Falguera, A. / Goday, J. (1909). L'arquitectura romànica a Catalunya. Volum I. Precedents: L'arquitectura romana, l'arquitectura Cristiana Pre-Romànica. Institut d'Estudis Catalans. Barcelona.
Ripoll, E. (1981). Prólogo. A: J. L. DE LA Pinta / J. Río-Miranda (1981). El poblado layetano de Puig Castellar, Sta. Coloma de Gramenet (Barcelona). Museo Municipal. Santa Coloma de Gramenet: 4-5.

Rovira, M. C. (1998). L'exhibició d'armes i cranis enclavats en els hàbitats ibers septentrionals. Cypsela, 12: $167-182$.

Rovira, M. C. / Codina, F. (2015). Caps tallats al sud d'Europa durant l'edat del ferro. A: Els caps tallats d'Ullastret. Violència $i$ ritual al món iber. Museu d'Arqueologia de Catalunya. Barcelona: 49-56.

Rubio, J. (1884). Nous descubriments arqueológichs á Cabrera de Mataró. L'Excursionista, 71: 340-342.

RuBio, J. (1886). Últimas excavaciones en la necrópolis ante-romana de Cabrera de Mataró. Butlletí de la Associació d'Excursions Catalana, 94-95: 133-137.

Rubio, J. (1887). Més monedes y altres objectes de la necrópolis de Cabrera. Butlletí de la Associació d'Excursions Catalana, 104-106: 96-105.

Rubio, J. (1888a). Noticia de una necrópolis anteromana descubierta en Cabrera de Mataró (Barcelona) en 1881. Memorias de la Real Academia de la Historia, XI: 669-789.

Rubio, J. (1888b). Armas de hierro halladas en la necrópolis ante-romana de Cabrera de Mataró. La España Regional, IV: 129-148.

RuBio, J. (1889). Antigüedades descubiertas últimamente en Cabrera de Mataró. Boletín de la Real Academia de la Historia, XIV (5): 417-426.

SADERRA, J. (1905) Ressenya històrica del santuari de Ntra. Sra. del Tura. Imprenta y librería de Joan Bonet. Olot.

SAGARRA, F. DE (1905a). Descubriments arqueològichs de Puig-Castellar, terme de Santa Coloma de Gramanet. Boletín de la Real Academia de Buenas Letras de Barcelona, 3/18: 88-91.

SAgARRA, F. DE (1905b). Descubriments arqueològichs de Puig-Castellar, terme de Santa Coloma de Gramanet (Continuació). Boletín de la Real Academia de Buenas Letras de Barcelona, 3/19: 160-165.

SAgARRA, F. DE (1905c). Descubriments arqueològichs de Puig-Castellar, terme de Santa Coloma de Gramanet (Acabament). Boletín de la Real Academia de Buenas Letras de Barcelona, 3/20: 233-237.

SAgARRA, F. (1908a). Los segells del rey en Jaume I. Boletín de la Real Academia de Buenas Letras de Barcelona, 4: 255-265.

SAgARra, F. (1908b). Sigilografia dels comtes d'Urgell. Boletín de la Real Academia de Buenas Letras de Barcelona, 4: 306-320. 
SAGARRA, F. (1909). Un nou segell de la comtesa dona Aurembiaix. Boletín de la Real Academia de Buenas Letras de Barcelona, 5: 1-3.

SAGARRA, F. (1910). Bibliografía sigilográfica española. Revue Internationale de Sigillographie (primer i únic número).

SAGARRA, F. (1911). Notes referents als segells del rei Martí. A: Centre Excursionista de Catalunya. Homenatge a la memòria del rei Martí. L’Avenç. Barcelona: 119-136.

SAGARra, F. (1912). Segells del temps de Jaume I. A: Congrés d'Història de la Corona d'Aragó, dedicat al rey en Jaume I y a la seua época. Francisco Altés. Barcelona: 978-1040.

SAGARRA, F. de (1916/1922/1932). Sigil.lografia catalana: Inventari, descripció $i$ estudi dels segells de Catalunya (3 vols.). Estampa d'Henrich. Barcelona.

SAgarra, J. M. de (1954). Memòries. Aedos. Barcelona.
Sanmartí, J. (2013). Josep de C. Serra-Ràfols i l'estudi de la cultura ibèrica. Butlletí de la Societat Catalana d'Estudis Històrics, 24: 35-53.

Sanmartí, J. / Gili, E. / Rigo, A. / de la Pinta, J. L. (1992). Els primers pobladors de Santa Coloma de Gramenet. Dels orígens al món romà. Museu Torre Balldovina. Santa Coloma de Gramenet.

Sanmartí, J. / Santacana, J. (2005). Els ibers del nord. Rafael Dalmau. Barcelona.

SERra, E. (2005). Ferran de Sagarra i de Siscar. Semblança biogràfica. Institut d'Estudis Catalans. Barcelona.

Serra RÀfols, J. DE C. (1926). La col.lecció Rubio de la Serna al Museu de Barcelona. Gaseta de les Arts, 54: 3-5.

Serra RÀFols, J. DE C. (1942). El poblamiento de la Maresma o Costa de Levante en la época anterromana. Ampurias, 4: 69-110.

VIÑAS, F. (1876). Arqueología prehistórica. Hallazgo en Caldas de Malavella. Revista de Gerona, 1: 49-52. 